\title{
STUDI BIOEKOLOGI IKAN KERAPU DI PERAIRAN PANTAI BARAT SULAWESI SELATAN
}

\author{
Utojo", Syarifuddin 'Tonnek", Suharyanto*' dan Andi Marsambuana Pirzan
}

\begin{abstract}
ABSTRAK
Penelitian ini bertujuan untuk mendapatkan informasi mengenai habitat, jenis makanan dan kebiasaan makan beberapa spesies ikan kerapu di Perairan Pantai Barat Sulawesi Selatan. Observasi habitat ikan dilakukan dengan penyelaman di perairan terumbu karang Podang-Podang menggunakan metode transek yang sejajar dengan garis pantai pada kedalaman 3-6 $\mathrm{m}$ dan 6-10 m. Sampel ikan sebanyak 30 ekor diperoleh dari tempat pendaratan ikan dan pasar di Pare-Pare, Barru dan Pangkep, yang dikumpulkan setiap bulan. Sampel tersebut kemudian dibawa ke laboratorium untuk diidentifikasi, diukur panjang dan bobotnya serta dibedah untuk mengetahui jenis makanan yang terdapat dalam lambung ikan dengan metode preferensi dan diukur panjang ususnya.

Berdasarkan hasil identifikasi, didapatkan 25 spesies ikan kerapu tercakup dalam enam genera. yaitu: Aethaloperea, Anyperodon. Cephalopholis, Epinephelus, Plectropomus, dan Variolu. Ikan kerapu hidup pada terumbu karang yang berasosiasi dengan jenis Porites sp., Acroporut sp.. Foliosa sp., sponge, pinctada, tridacna, dan lainnya. Lambung ikan kerapu berisi jeni. makanan yang terdiri atas Sargocentron sp. (ikan karang) 80.0\%. Sardinella sp. (ikan tembang) $36,7 \%$. golongan krustase (kepiting dan udang kecil) 19,3\%, dan Cephalopoda (cumi-cumi) 6.7"
\end{abstract}

\section{ABSTRACT: Study on ecobiology of grouper in west coastal waters of South Sulawesi. By: Utojo, Syarifuddin Tonnek, Suharvanto and Andi Marsambuana Pirzan.}

The experiment was aimed at finding out information of habitat as well as food and feeding habit of some grouper species in the western part of South Suluvesi coastal waters. Fishing ground of grouper distribution was examined in Podang-Podang coral reef waters by transect method along the coastal line at the depths of 3-6 $\mathrm{m}$ and 6-10 $\mathrm{m}$. Thirty fish were collected every month firom fish landing places (FLP) and markets in Pare-Pare, Barru and Pangkep. The fish samples were brought to the laboratory for identification for food, feeding hab it and measurement of body weight and total length.

There were 25 species of groupers belonging to 6 genera (Acthaloperca, Anyperodon, Cephalopholis, Epinephelus, Plectropomus, and Variolal). The grouper fish live in (oral reet waters in association with Porites sp. Acropora sp., Foliosa sp., sponges, oysters, giant clams. and others. Food habit of grouper consisted of 80\% Sargocentron sp., 36. 7" Sardinella sp. 19.3" Crustaceans, and 6.7" "Cephalopods.

KEYWORDS: habitat, food and feeding habits, grouper, west coastal waters of South Sulawesi.

\section{PENDAHULUAN}

Ikan kerapu merupakan hasil perikanan perairan karang yang mempunyai nilai ekonomis tinggi seperti ikan kerapu lumpur (Epinephelus suillus), kerapu macan (E. fuscoguttatus), kerapu alis (Cheilinus undulatus), dan kerapu sunu (Plectropomus maculatus). Saat ini pangsa pasar sepenuhnya dipasok dari hasil penangkapan di alam. Alternatif yang dapat dilakukan untuk meng. antisipasi hal tersebut di atas adalah pengembangan usaha budi daya. Untuk itu diperlukan penelusuran terhadap aspek bioekologi ikan kerapu melalui seleksi spesies budi daya, habitat, jenis makanan dan kebiasaan makan.
Ikan kerapu di dunia internasional dikenal sebagai groupers, rockcods, hinds dan seabasses yang dimasukkan ke dalam famili Serranidae. subfamili Epinephelinae yang terdiri atas 15 genus dan mencakup 159 spesies (Heemstra \& Randall. 1993). Kohno et al. (1990) melaporkan bahwa sebanyak 46 spesies termasuk ke dalam tujuh genus antara lain Aethaloperca, Anyperodon. Cephalopholis, Cromileptes, Epinephelus, Plectropomus, dan Variola yang dikumpulkan dan diidentifikasi dari perairan Filipina dan Indonesia.

Ikan kerapu ditemukan di perairan tropis clan subtropis, umumnya menghuni terumbu karang yang terutama memiliki produktivitas tinggi.

Peneliti pada Balai Penelitian Perikanan Pantai 
tetapi beberapa spesies di antaranya hidup di daerah estuari. Ikan tersebut memanfaatkan habitat ini sebagai tempat hidup, bertumbuh dan mencari makan. Kerapu berasosiasi dengan substrat yang keras dalam perairan, walaupun ikan mudanya ditemukan di padang lamun dan beberapa yang telah dewasa menelusuri perairan yang berpasir dan berlumpur (Heemstra \& Randall, 1993).

Ikan kerapu tergolong ikan buas, hidup menyendiri (soliter), dan banyak terdapat di daerah terumbu karang serta muara sungai (Kuiter, 1992) dan pada umumnya memakan berbagai jenis ikan, krustase, dan cephalopoda (Heemstra \& Randall, 1993). Ikan kerapu menyenangi naungan (shelter) sebagai tempat bersembunyi dan menghindar dari sinar matahari langsung. Ikan kerapu mencari makan dengan cara menelan mangsa dari tempat persembunyian mangsa tersebut, setelah itu kembali lagi ke tempat semula. Kemampuan kerapu menelan mangsa berbeda-beda sesuai spesies. Jenis makanan yang disenangi kerapu adalah ikan, cumi-cumi dan udang yang berukuran 10 sampai $25 \%$ dari ukuran tubuhnya. Makanan utama ikan kerapu yang belum dewasa adalah fauna bentik yang berada di daerah terumbu karang dari perairan yang dangkal, sedangkan untuk ikan kerapu yang berukuran besar adalah pemakan ikan-ikan kecil dan invertebrata pelagis. Banyaknya insang menunjukkan bahwa ikan ini bersifat filter feeder (Sukarno et al., 1981).

Bioekologi ikan kerapu di perairan pantai barat Sulawesi Selatan perlu diketahui dalam rangka pengembangan diversifikasi spesies potensial budi daya dan pengelolaan sumber daya ikan kerapu.

\section{BAHAN DAN METODE}

Penelitian mengenai habitat ikan kerapu dilakukan di daerah terumbu karang perairan pantai Podang-Podang, Pangkep pada dua lokasi yang dilakukan sebulan dua kali selama tiga bulan. Metode yang digunakan adalah sensus visual yang dikembangkan oleh Amesbury et al. (1979). Pada setiap lokasi penelitian ditarik garis transek sepanjang $50 \mathrm{~m}$ sejajar dengan garis pantai pada kedalaman 3 sampai $10 \mathrm{~m}$. Dengan jalan penyelaman, pencatatan dilakukan terhadap jumlah dan jenis ikan kerapu yang berada di sepanjang garis transek. Hal ini digunakan untuk mengetahui habitat dan kebiasaan makan serta tingkah laku ikan kerapu. Identifikasi jenis ikan kerapu langsung dilakukan sewaktu penyelaman dengan berpedoman pada buku ikan karang (Amesbury \& Myers, 1982; Kohno et al., 1990; Heemstra \& Randall, 1993). Kelimpahan setiap jenis ikan kerapu masuk dalam daerah seluas $25 \mathrm{~m}$ di sebelah kiri dan kanan garis transek. Peubah lain yang diamati adalah suhu dan salinitas di dasar perairan terumbu karang. Penelitian jenis makanan, kebiasaan makan dan identifikasi jenis ikan kerapu dilakukan dengan pengamatan contoh yang diperoleh dari hasil tangkapan nelayan di pasar dan tempat pendaratan ikan di Pare-Pare, Barru dan Pangkep yang mewakili Perairan Pantai Barat Sulawesi Stlatan. Pengambilan sampel ikan sebanyak 30 ekor dilakukan setiap bulan. Sampel yang didapatkan dari pasar dan tempat pendaratan ikan dimasukkan ke dalam cool box dan pengamatan selanjutnya dilakukan di Laboratorium Balai Penelitian Perikanan Pantai (Balitkanta), Maros. Dengan cara pembedahan ikan, isi perutnya dikeluarkan dan diawetkan dengan formalin $10 \%$. Peubah yang cliamati meliputi identifikasi spesies. jumlah, panjang total, bobot badan, panjang usus, panjang usus relatif dan jenis makanan. Panjang total badan dan panjang usus ikan masing-masing diukur menggunakan mistar dengan tingkat ketelitian 0,1 cm, sedangkan bobot badan ikan menggunakan timbangan elektrik Sartorius dengan tingkat ketelitian 0,1 mg. Perbandingan panjang usus dan badan ikan (panjang usus relatif) menggunakan metode Hepher (1988) dengan rumus:

$$
R G L=\frac{G L}{R L}
$$

di mana:

RGL = panjang relatif

$\mathrm{GL}=$ panjang usus $(\mathrm{cm})$

$\mathrm{RL}$ = panjang badan $(\mathrm{cm})$

Sementara metode frekuensi kejadian yang digabungkan dengan gravimetri untuk menentukan index preference digunakan untuk mengetahui tingkat pemilihan makanan ikan kerapu (Effendie, 1979).

\section{HASIL DAN BAHASAN}

\section{Habitat}

Hasil pengamatan mengenai peubah kualitas air untuk habitat ikan kerapu disajikan pada Tabel 1. Tabel 1 memperlihatkan bahwa suhu dan salinitas air pada dua lokasi pengamatan relatif sama, bail: pada kedalaman 3-6 m maupun 6-10 m. Di daerah terumbu karang di mana dilakukan pengukuran suhu dan salinitas ditemukan populasi ikan karang yang termasuk di dalamnya terdapat beberapa spesies ikan kerapu (Tabel 2). Hasil observasi penyelaman pada lokasi pengamatan pertama 
Tabel 1. Peubah kualitas air untuk habitat ikan kerapu di lokasi penelitian daerah terumbu karang dengan kedalaman 3-6 $\mathrm{m}$ dan 6-10 $\mathrm{m}$.

Table 1. Water quality variable of grouper habitat in the experiment location at coral reef area ut the depths of 3-6 $\mathrm{m}$ and $6-10 \mathrm{~m}$.

\begin{tabular}{ccccc}
\hline \multirow{2}{*}{$\begin{array}{c}\text { Peubah } \\
\text { Variables }\end{array}$} & \multicolumn{4}{c}{$\begin{array}{c}\text { Kedalaman terumbu karang (m) } \\
\text { Depth of coral reef }(\mathrm{m})\end{array}$} \\
\cline { 2 - 5 } & \multicolumn{3}{c}{ Lokasi I (Location I) } & Lokasi II (Location II) \\
\cline { 2 - 5 } & $\mathbf{( 3 - 6 )}$ & $\mathbf{( 6 - 1 0 )}$ & $(3-6)$ & $(6-10)$ \\
\hline Suhu (Temperature) ('C) & $30-31$ & $28-30$ & $29-30$ & $28-29$ \\
Salinitas (Salinity') (ppt) & $33-34$ & $34-35$ & $33-34$ & $34-35$ \\
\hline
\end{tabular}

dengan kedalaman 3-6 m tidak ditemukan spesies kerapu, tetapi spesies kerapu tersebut hanya ditemukan pada kedalaman 6-10 m. Hal ini disebabkan kondisi terumbu karang sebagai habitat kerapu di permukaan $(3-6 \mathrm{~m})$ terdiri atas $50 \%$ karang mati dan $20 \%$ potongan karang dan pasir akibat adanya penangkapan kerapu menggunakan potasium sianida dan bahan peledak, sehingga memungkinkan spesies kerapu bermigrasi ke arah yang lebih dalam $(6-10 \mathrm{~m})$ dengan kondisi terumbu karang yang lebih baik (30\% karang hidup) dan dapat berasosiasi dengan organisme lain. Pada lokasi pengamatan ke dua baik pada kedalaman 3-6 m maupun 6.10 m ditemukan spesies kerapu. Hal ini disebabkan baik pada kedalaman 3-6 m maupun $6.10 \mathrm{~m}$ kondisi terumbu karang sebagai habitat kerapu cukup baik $60 \%$ karang hidup dan organisme lain) dan jenis kerapu dapat berasosiasi dengan organisme lain.

Kondisi terumbu karang sebagai habitat kerapu pada lokasi I diperkirakan $50 \%$ karang mati, $20 \%$ terdiri atas potongan karang dan pasir, $30 \%$ karang hidup dan organisme lain. Rusaknya kondisi terumbu karang ini diduga disebabkan aktivitas nelayan mencari ikan menggunakan bahan peledak dan pemasangan jangkar sebagai tempat bersandarnya kapal. Di samping itu juga ditemukan bahwa penangkapan ikan kerapu menggunakan potasium sianida sebagai pembius ikan. Sistem penangkapan seperti ini juga telah dilakukan terhadap ikan hias (Syam et al., 1993). Potasium sianida merupakan bahan kimia yang larut dalam air dan dapat merusak lingkungan perairan karang terutama biota karạng (Syam \& Edrus, 1996). Jenis dan penyebab rusaknya terumbu karang sebagai habitat ikan antara lain adalah kegiatan pemukatan; peledakan pada pencurian ikan atau penambang. an untuk material industri. tungku kapur, atau lainnya; penangkapan menggunakan bahan kimia: rekreasi dan pariwisata bahari seperti koleksi. penjangkaran, gusuran perahu, atau lainnya. Jika habitat yang rusak skalanya kecil dan terlokalisasi. maka rehatbilitasi dengan cara pemasangan turumbu buatan dapat berpengaruh pada perbaikannya (Ilyas et al., 1994). Lokasi I di kawasan terumbu karang berjarak sekitar $100 \mathrm{~m}$ dari tempat pemukiman nelayan dan merupakan alur lalu lintas pelayaran nelayan, sehingga kecenderungan terjadi pengaruh langsung dari penduduk terhadap pencemaran lingkungan perairan. Kondisi seperti ini sebagian besar terjadi di kawasan terumbu karang pada kedalaman 3-6 m, sehingga populasi ikan kerapu dan organisme lain banyak yang bermigrasi ke kawasan terumbu karang lebih dalam pada kedalaman 6-10 m yang masih hidup dan lestari serta didapatkan batu karang besar berbentuk gua yang di sekitarnya terdapat lubang-lubang ditumbuhi atau berasosiasi dengan terumbu kalrang jenis Porites sp., Acropora sp., foliosa. sponge. pinctada, tridacna dan lainnya. Sedangkan jumlah ikan kerapu yang ditemukan umumnya berkisar 1-4 ekor lengan panjang badan berkisar $15-30 \mathrm{~cm}$. Hal ini sesuai dengan pendapat Kuiter (1992). bahwa ikan kerapu tergolong ikan buas yang rakus dan sifat hidupnya menyendiri (soliter) serta menyenangi naungan (shelter) sebagai tempat bersembunyi dan menghindar dari sinar matahari langsung.

Kondisi terumbu karang sebagai habitat kerapu pada lokasi II diperkirakan 20\% karang mati dan $20 \%$ terdiri atas potongan karang dan pasir. (i) \% karang hidup dan organisme lain. Kerusaliun kondisi terumbu karang pada kawasan ini diduga hanya diakibatkan hasil buangan jangkar uleh nelayan sebagai tempat bersandarnya kapal dalam mencari ikan. Jarak antara pulau sebagai tempat pemukiman nelayan dan kawasan terumbu karang pada lokasi II $(500 \mathrm{~m})$, serta kawasan tericbut 
Tabel 2. Jumlah dan spesies ikan kerapu, vegetasi karang, dan ikan karang lain di lokasi I dan II pada terumbu karang dengan kedalaman $3.6 \mathrm{~m}$ dan $6.10 \mathrm{~m}$.

Table 2. Number and species of grouper, coral vegetation, and other coral fish in location I and II at coral reef with the depth of $3-6 \mathrm{~m}$ and $6.10 \mathrm{~m}$.

\begin{tabular}{|c|c|c|c|c|}
\hline \multirow{3}{*}{$\begin{array}{l}\text { Peubah } \\
\text { Variables }\end{array}$} & \multicolumn{4}{|c|}{$\begin{array}{c}\text { Kedalaman terumbu karang }(\mathrm{m}) \\
\text { Depth of coral reef }(\mathrm{m})\end{array}$} \\
\hline & \multicolumn{2}{|c|}{ Lokasi I (Location I) } & \multicolumn{2}{|c|}{ Lokasi II (Location II) } \\
\hline & $(3-6)$ & $(6-10)$ & $(3-6)$ & $(6-10)$ \\
\hline $\begin{array}{l}\text { Kondisi terumbu pada habitat kerapu (\%) } \\
\text { Coral condition of grouper habitat (\%) } \\
\text { Spesies dan jumlah kerapu (ekor) } \\
\text { Species and numbers of grouper (ind.): }\end{array}$ & $50 \& 20$ & 30 & $20 \& 20$ & 60 \\
\hline - Chephalopholis miniata & - & 1 & 1 & - \\
\hline - Epinephelus areolatus & - & 2 & 2 & \\
\hline - Epinophelus corallicola & - & 3 & 1 & 2 \\
\hline - Epinephelus fuscogutatus & . & 3 & - & 3 \\
\hline - Epinephelus maculatus & - & 1 & - & 2 \\
\hline Epinephelus merra & - & 2 & - & 2 \\
\hline - Epinephelus microdon & - & 4 & 3 & - \\
\hline - Epinephelus ongus. & - & 2 & - & 1 \\
\hline - Plectropomus leopardus & - & 1 & - & 2 \\
\hline - Plectropomus maculatus & & 1 & & 2 \\
\hline - Plectropomus oligocanthus & - & 1 & - & 1 \\
\hline $\begin{array}{l}\text { Tumbuhan karang (Coral vegetation): } \\
\text { Karang masif (Massive coral): }\end{array}$ & & & & \\
\hline - Porites luthea & + & - & + & + \\
\hline $\begin{array}{l}\text { - Acropora sp. } \\
\text { Karang polip (Foliose coral): }\end{array}$ & + & - & + & - \\
\hline $\begin{array}{l}\text { Echinophora sp. } \\
\text { Alga (Algae): }\end{array}$ & - & + & + & + \\
\hline - Poralithon sp. & - & + & + & + \\
\hline - Gelidiopsis sp. & - & + & + & + \\
\hline $\begin{array}{l}\text { Ikan siganid (Siganid fish): } \\
\text { - Siganus vermiculatus }\end{array}$ & . & 15 & 10 & 13 \\
\hline - Siganus javus & - & 13 & 9 & 11 \\
\hline Ikan ekor kuning (Yellow tail fish): & & & & \\
\hline $\begin{array}{l}\text { - Seriola sp. } \\
\text { Ikan kakak tua (Kakak tua fish): }\end{array}$ & - & 21 & 12 & 16 \\
\hline - Scarida sp. & & 17 & 10 & 14 \\
\hline
\end{tabular}

Note: $(-)=$ tidak ditemukan $($ no found $) ;(+)=\operatorname{ditemukan~}($ found $)$

Loc. I: $(3-6 \mathrm{~m})$ ) dead coral of $50 \%$, coral fragment \& sand of $20 \%(6-10 \mathrm{~m})$ : life coral \& others organism of $30 \%$

Loc.II: (3-6 m): dead coral of $20 \%$, coral fragment \& sand of $20 \%(6-10 \mathrm{~m})$ : life coral \& others organism of $60 \%$

bukan merupakan alur lalu lintas pelayaran nelayan, sehingga kecenderungan mencari ikan dengan melakukan peledakan terumbu karang dan pengaruh langsung dari penduduk terhadap kemungkinan pencemaran lingkungan perairan dirasakan masih kurang. Apabila dilihat dari penyebaran populasi ikan kerapu yang ditemukan di kawasan terumbu karang pada lokasi II nampak menempati daerah pada kedalaman 3-6 m dan 6-10 m. Jenis ikan kerapu pada lokasi I dan II yang ditemukan didominasi oleh Epinephelus microdon. Spesies ikan kerapu yang menempati kawasan 
terumbu karang lokasi II pada kedalaman $3.6 \mathrm{~m}$ antara lain Cephalopholis miniata, Epinephelus areolatus, E. corallicola, dan E. microdon, sedangkan spesies yang lain ditemukan di kawasan terumbu karang pada kedalaman $6.10 \mathrm{~m}$. Jumlah ikan kerapu yang ditemukan berkisar 1-3 ekor dengan panjang badan berkisar $10-50 \mathrm{~cm}$. Berdasarkan pengamatan tingkah laku kerapu secara visual di daerah terumbu karang, ikan tersebut terlihat hidupnya soliter, berdiam diri secara pasif di dalam lubang dan hanya pada saat mencari makan atau aktivitas yang lain, ikan tersebut keluar dari lubang atau sarang lalu menjelajahi karang dengan radius lebih kurang $10 \mathrm{~m}$ dari sarang dan kemudian kembali ke tempatnya semula.

\section{Kelimpahan Ikan Kerapu}

Di perairan Pantai Barat Sulawesi Selatian ditemukan 25 spesies yang mencakup (1n:am genera yaitu Aethaloperca, Anyperodon, Cepluto. pholis, Epinephelus, Plectropomus, dan V'ariola serta 159 individu (Tabel 3). Menurut Kohno el al. (1990) dan Sunyoto (1994), ikan kerapu yang hidup pada berbagai tipe habitat di perairan Indonesia dan Filipina terdapat 46 spesies yang tercakup ko dalam enam genera, yaitu Aethalopera. Anyperodon, Cephalopholis, Cromileples, Epinephelus, Plectropomus, dan Variola. Data hasil pengumpulan sampel ikan kerapu di Perailan Pantai Barat Sulawesi Selatan tidak ditemukan genus Cromileptes sehingga hanya terdapat conam genera. Kelimpahan ikan kerapu yang didapatkan

Tabel 3. Spesies. jumlah, kisaran panjang total, bobot badan, panjang usus rata-rata. dan panjang usus relatif ikan kerapu.

Table 3. Species, number, ranges of total length, body weight, average gut length, and relative gut length (RGL) of grouper.

\begin{tabular}{|c|c|c|c|c|c|}
\hline $\begin{array}{l}\text { Spesies } \\
\text { Species }\end{array}$ & $\mathrm{N}$ & $\begin{array}{c}\text { Panjang } \\
\text { total } \\
\text { Total length } \\
\text { (cm) }\end{array}$ & $\begin{array}{l}\text { Bobot tubuh } \\
\text { Body weight } \\
\text { (g) }\end{array}$ & $\begin{array}{c}\text { Panjang } \\
\text { usus } \\
\text { Gut length } \\
(\mathrm{cm})\end{array}$ & $\begin{array}{c}\text { Panjang relatif } \\
\text { usus } \\
\text { Relative gut } \\
\text { length }\end{array}$ \\
\hline Acthaloperca rogaa & 1 & 41.0 & $1,300.96$ & 34.5 & 0.84 \\
\hline Anyperodon leucogrammicus & 2 & $26.5-30.5$ & $201.53-288.86$ & $17.3-19.5$ & 0.65 \\
\hline Cephalopolis argus & 1 & 32.7 & 672.00 & 43.5 & 1.33 \\
\hline C. aurantia & 2 & $18.4-37.4$ & $96.70-843.45$ & $15.8-23.4$ & 0.70 \\
\hline C. boenack & 3 & $15.1-17.3$ & $58.89-66.66$ & $5.9 \cdot 7.3$ & 0.41 \\
\hline C. cynostigma & 1 & 27.5 & 334.94 & 15.7 & 0.57 \\
\hline C. lcopardus & 2 & $22.1-26.2$ & $129.89-253.84$ & $18.7-20.1$ & 0.80 \\
\hline C. miniata & 9 & $27.3-35.3$ & $312.10-688.35$ & $23.5-28.2$ & 0.83 \\
\hline C. sexmaculata & 1 & 32.4 & 558.82 & 23.6 & 0.72 \\
\hline C. sonnerati & 3 & $21.5 \cdot 44.7$ & $125.38-1.613 .55$ & $12.6-21.0$ & 0.51 \\
\hline Epinephelus areolatus & 15 & $16.4-49.5$ & $55.90-1.600 .00$ & $5.3-11.7$ & 10.26 \\
\hline E. bleekeri & 1 & 31.1 & 416.91 & 24.5 & 0.72 \\
\hline E. corallicola & 3 & $22.7-32.8$ & $163.80-482.44$ & $37.1-43.7$ & 1. 16 \\
\hline E. fuscoguttatus & 27 & $24.9-53.5$ & $517.77 \cdot 2,414.54$ & $49.6-59.0$ & 1.39 \\
\hline E. merra & 8 & $21.3-32.0$ & $169.10-5339.99$ & $10.9-16.3$ & 0.51 \\
\hline E. microdon & 17 & $17.2-40.9$ & $68.78-841.06$ & $39.4-49.8$ & 1.54 \\
\hline E. ongus & 5 & 26.8 .46 .0 & $300.95-1.465 .94$ & $22.9-32.8$ & $0.7 T$ \\
\hline E. quoyanus & 5 & $20.0-32.2$ & $112.07-158.77$ & $15.2-20.0$ & 0.67 \\
\hline E. suillus & 9 & $26.0-49.7$ & $257.88-1,800.00$ & $20.3-29.1$ & 0.65 \\
\hline E. tauvent & 23 & $26.4-66.0$ & $275.00-4.300 .00$ & $48.8-64.2$ & 1.22 \\
\hline Plectopoma laevis & 2 & $33.3-49.9$ & $425.27 \cdot 1,422.88$ & $39.5-45.4$ & 1.02 \\
\hline$P$. leopardus & 9 & $16.5-29.8$ & $54.61-311.20$ & $8.7-15.8$ & $0.5: 3$ \\
\hline P. maculatus & 3 & $31.9-39.0$ & $393.64-666.04$ & $12.9-20.6$ & 0.17 \\
\hline P. oligaranthus & 2 & $43.7-44.0$ & $864.36-1,029.23$ & $27.1-29.0$ & 0.61 \\
\hline Variola albimarginata & 5 & $28.9-38.7$ & $253.39-535.18$ & $11.4-17.5$ & 0.43 \\
\hline
\end{tabular}


di perairan pantai barat Sulawesi Selatan didominasi antara lain oleh Epinephelus fuscoguttatus, E. tauvina, E. microdon, E. areolatus, C. miniata, E. suillus, P. leopardus, dan E. merra. Diduga bahwa melimpahnya ikan kerapu tersebut disebabkan oleh kondisi perairan terumbu karang yang kaya dengan ketersediaan jenis makanan dan sesuai sebagai tempat hidupnya, berkurangnya tingkat kompetisi dan predator, serta bukan merupakan kawasan utama penangkapan.

Beberapa spesies ikan kerapu yang didapatkan melimpah di perairan pantai barat Sulawesi Selatan (Tabel 3), baik jumlah individu, ukuran bobot ikan maupun panjang usus relatif yang tinggi antara lain E. fuscoguttatus, E. tauvina, E. microdon, E. areolatus, dan E. suillus, dapat digunakan sebagai alternatif dalam pemilihan komoditas potensial budi daya perikanan laut. $P$. leopardus, C. miniata, dan E. merra walaupun jumlah individunya banyak ditemukan di perairan pantai tersebut, namun ukuran ikannya relatif kecil dan umumnya dalam keadaan matang gonad, sehingga kurang potensial untuk komoditas budi daya. Ditinjau dari kelimpahan ikan kerapu di perairan ini yang dihubungkan dengan ukuran dan sifat reproduksinya, maka $E$. areolatus memiliki potensi untuk dibudidayakan, sedangkan $E$. fuscoguttatus dan E. tauvina telah dibudidayakan baik di keramba jaring apung di laut maupun di tambak. Untuk ikan kerapu jenis P. leopardus, C. miniata dan $E$. merra sering ditemukan dengan ukuran yang relatif kecil dalam keadaan matang gonad, sehingga kurang menunjang untuk dikembangkan sebagai komoditas budi daya.

\section{Panjang Usus Relatif, Makanan dan Cara Makan}

Hasil pengukuran panjang usus ikan kerapu (Tabel 3) menunjukkan bahwa di antara semua spesies ikan kerapu yang ditemukan, panjang usus relatif tinggi terdapat pada E. microdon, E. corallicola, E. fuscoguttatus, C. argus, E. tauvina, dan $P$. laevis. Spesies ikan kerapu yang mempunyai panjang usus lebih panjang dibanding dengan panjang badannya diduga memiliki laju pertumbuhan yang cepat. Hal ini disebabkan oleh aktivitas dan kebiasaan dalam tingkat pemilihan jenis makanan. Panjang usus relatif ikan kerapu sebagai ikan karnivora berkisar 0,26-1,54. Menurut Zonneveld et al. (1991), ikan karnivora memiliki panjang usus relatif $0,2-2,51$; omnivora $0,6-8,0$; dan herbivora 0,8-15. Selain itu usus ikan kerapu yang diamati mempunyai lipatan-lipatan yang dapat menambah luas permukaan dinding usus ikan dan berfungsi dalam penyerapan makanan. Menurut Lagler (1977) kapasitas penyerapan makanan meningkat dengan meningkatnya luas permukaan dinding usus melalui pengembangan klep spiral lipatan usus.

Hasil analisis isi perut ikan dari 150 ekor ikan kerapu tertera pada Tabel 4. Pada Tabel 4 terlihat bahwa makanan utama ikan kerapu berupa ikan karang jenis Sargocentron sp. yang ukurannya berkisar $5.1 .5 \mathrm{~cm}$ dan populasinya berlimpah di perairan karang; kemudian ikan tembang, golongan krustase (kepiting dan udang kecil) serta golongan cephalopoda (cumi-cumi). Di samping jenis tersebut, juga ditemukan golongan makanan yang tidak dapat diidentifikasi pada semua lambung ikan yang berisi. Pada pengamatan tersebut diperkirakan bahwa jenis ini berasal dari jenis makanan seperti ikan karang, tembang. kepiting dan udang kecil serta cumi-cumi yang telah mengalami proses pencernaan lebih lanjut.

Berdasarkan jenis dan tingkat pemilihan makanannya tersebut, ikan kerapu tergolong karnivora dan predator terhadap ikan yang berukuran kecil dan cara makannya mencaplok dengan tipe mulut yang umumnya terminal.

Tabel 4. Tingkat pemilihan makanan ikan kerapu di perairan pantai barat Sulawesi Selatan.

Table 4. Food preference of grouper in west coastal waters of South Sulawesi.

\begin{tabular}{lc}
\hline \multicolumn{1}{c}{ Jenis makanan } & $\begin{array}{c}\text { Indeks pemilihan } \\
\text { Food }\end{array}$ \\
\hline Sargocentron sp. & 80.0 \\
Sardinella sp. & 36.7 \\
Krustase (Crustaceans) & 19.3 \\
Cephalopoda (Cephalopods) & 6.7 \\
\hline
\end{tabular}




\section{KESIMPULAN}

Ikan kerapu hidup secara soliter di daerah terumbu karang yang berasosiasi dengan jenis Porites sp.. Acropora sp., foliosa. sponge, pinctada, tridacna, dan lainnya.

Di Perairan Pantai Barat Sulawesi Selatan ditemukan 25 spesies yang mencakup enam genera, yaitu Aethaloperca, Anyperodon, Cephalopholis, Epinephelus, Plectropomus, dan Variola.

Spesies ikan kerapu yang potensial untuk budidaya antara lain: $C$. argus, E. corallicola, $E$. fuscoguttatus, E. microdon, E. tauvina, dan P. laevis.

Makanan utama ikan kerapu berupa ikan karang jenis Sargocentron sp. yang berukuran 5-15 $\mathrm{cm}$.

\section{DAFTAR PUSTAKA}

Amesbury. S.S. Lassuy. D. R.. Myers. R.F. and Tynzik. V. 1979. A Survey of the Fish Resources of Sipan Lagoon. University of Guam. Marine Laboratory. $58 \mathrm{pp}$.

Amesbury. S.S. and Myers. R.F. 1982. Guide to the Coastal Resourees of Guam. The Fishes University of Guam. Marine Laboratory. 1:141 pp.

Effendie. M.I. 1979. Metoda Biologi Perikanan. Cetakan Pertama. Yayasan Dewi Sri. Bogor. 112 hal

Heemstra. P.C. and Randall. J.E. 1993. FAO species catalogue. Vol. 16. Grouper of the world (Family Serranidae. Subfamily Epinephelinae). An ammotated \& illustrated catalogue of the grouper. rockcod. kind. coral grouper and lyretoil species known to date. FAO Fisheries Synopsis No. 125. Vol. 16 Rome.
Hepher, B. 1988. Nutrition of Pond Fishes. Cambridge University Press. New York. New Rocholle. Melbourne. Sydney. 388 pp.

Ilyas. S.. Wasilum, Wagiyo. K., Suprapto. Murnivati. dan Mubarak. H. 1994. Pedoman Teknis Pengeloluten Terumbu Buatan. Seri Pengembangan Hasil Penelirian Perikanan No.PHP/KAN/PT.29/1994. Badan Penelitian dan Pengembangan Pertanian. Jakarta. 90 hal.

Kohno, H. Duray, M. dan Sunyoto. P. 1990. A. Field Guide to Groupers of Southeast Asia. Pusat Penelitian \& Pengembangan Perikanan PHP/KAN/PT.No. 1 I/ 1990. Jakarta. $26 \mathrm{pp}$.

Kuiter. R.K. 1992. Tropical Reef Fishes of the Wristern Pacific Indonesia and Adjacent Waters. PT. Gramedia Pustaka Utama. Jakarta. 314 hal.

Lagler. K.E. Bardach. J.E.. Willer, R.R. and Passino. D.R.M. 1977. Ichtyology'. John Wiley and Sons. New York. Santa Barbara. London. Sydney. Toronto, 506; $\mathrm{pp}$.

Sukarno. Hutomo, M.. Moosa, M.K. dan Darsono. P.1981. Terumbu Karang di Indonesia. LON-L.IPI. Jakartis. 102 hal.

Syam. A.R., Edrus, I.N. dan Bustaman. 1993. Percobaan penangkapan. penanganan dan transportasi ikan hias di Nusa Laut. Maluki Tengah. J. Penelitian Perikanan Laut. Jakiatal. 83:59-66.

Syam. A.F. dan Edrus. I.N. 1996. Kondisi terumbu karang di perairan Hila dan Morela (Pulau Ambon) serta bagian tenggara Pulau Batanta (Sorong). J Ponelit. Perikan. Indones., II(3):1-11.

Sunyoto. P. 1994. Pembesaran Kerapu dengan Keramba Jaring Apung. PT Penebar Swadaya. Jakarta. 6i hal.

Zonneveld. N.. Huisman. F.A. and Boon. J.H. 1991 Prinsip-prinsip Budidaya Ikan. PT Gramedia Pustaka Utama. Jakarta. 318 hal. 